\title{
EDUCATION INCREASES THE PROPORTION OF INFANTS ACHIEVING TARGET TEMPERATURE DURING TRANSPORT FOR THERAPEUTIC HYPOTHERMIA, WITHOUT THE NEED FOR IN-TRANSIT ACTIVE COOLING
}

\author{
A. Wynn-Davies ${ }^{1,2}$, J. Gallagher ${ }^{2}$, M. Palframan ${ }^{2}$, N. Davey ${ }^{2}$, A. Leslie $^{2}$ \\ ${ }^{l}$ Neonatal Unit, Nottingham University Hospitals, Nottingham, ${ }^{2}$ Centre Neonatal Transport Service, \\ University Hospitals Leicester, Leicester, UK
}

Background and aims: Therapeutic hypothermia for moderate or severe hypoxic ischaemic encephalopathy is a treatment for which infants born in Level 1 and 2 units will need transfer to a Level 3 centre. The target temperature should be achieved within six hours. Our aim was to improve the time it took to transfer these infants, and their temperature management, without using active cooling equipment in transit.

Methods: We prospectively collected data over two periods. The first from 19/4/10 to 19/9/10, and the second from $1 / 11 / 10$ to $31 / 1 / 11$. After the first period education was delivered to improve team understanding of transporting infants for cooling. This was given to transport nurses, neonatal unit's staff and lead clinicians for Trent Perinatal and Central Newborn Networks. We compared data on timing and temperature between the two periods.

Results: Thirteen babies were referred and moved for cooling in the first period. Two were excluded, one due to active cooling at the referring unit, and one for lack of data. Ten babies were referred in the second period. One was excluded as he did not fulfil cooling criteria.

The number of babies reaching cooling temperatures (33.0-34.0) during transfer significantly improved between the two time periods $(\mathrm{p}=0.04)$. The change in temperature from referral to arrival at a cooling centre, and the age of the infant on arrival at a cooling centre show an improving trend.

Conclusions: Passive cooling alone when used with educated NICU and transport teams may be sufficient to achieve target temperature and time goals. 